"Educação como prática de Liberdade": cartas da Amazônia para o mundo!

ANPEd - Associação Nacional de Pós-Graduação e Pesquisa em Educação

9256 - Resumo Expandido - Trabalho - 40ª Reunião Nacional da ANPEd (2021)

ISSN: 2447-2808

GT13 - Educação Fundamental

CORPOREIDADE E O COTIDIANO ESCOLAR: OS GIRASSÓIS E AS POSSÍVEIS

INTERVENÇÕES NO ATO DE CUIDAR

Marcelo Paraiso Alves - UFRJ - Universidade Federal do Rio de Janeiro

Amparo Villa Cupolillo - UNIVERSIDADE FEDERAL RURAL DO RIO DE JANEIRO

\title{
1 INICIANDO O DIÁLOGO
}

Figura 1 - Componentes do grupo Girassóis

\section{COLETIVO GIRASSÓIS DO CLEUSA ENCANTA, LEVANDO MENSAGEM DE ESPERANÇA}

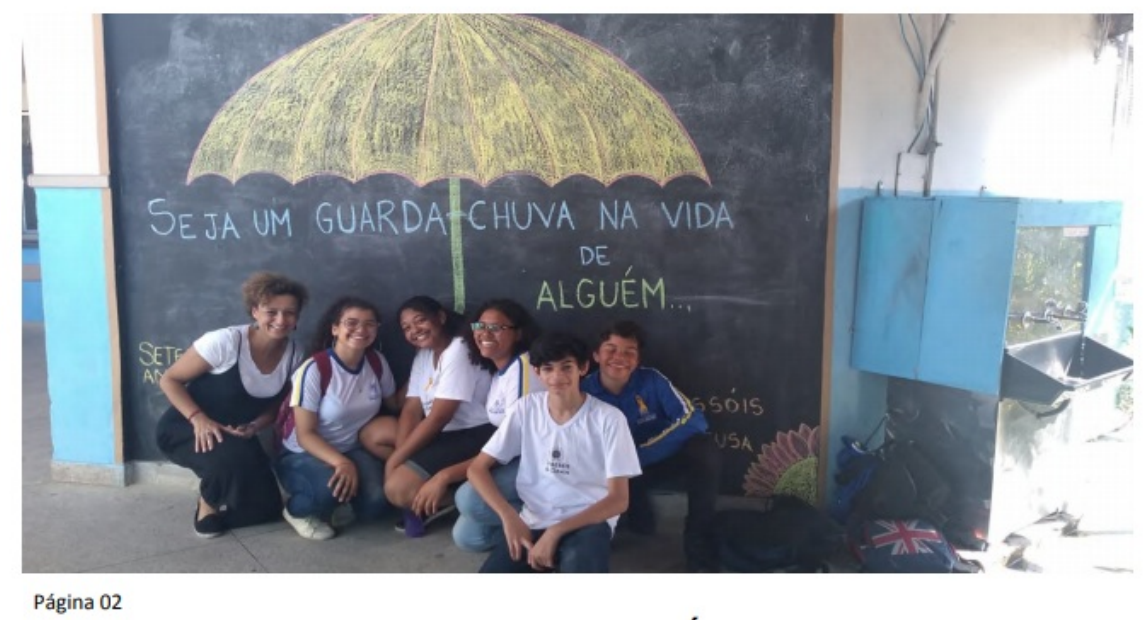

FONTE: Jornal da escola - Notícias[1]

O presente trabalho objetiva visibilizar o modo como os praticantespensantes[2] de uma escola pública do interior do estado do Rio de Janeiro, ao longo do ano de 2019, enfrentaram os problemas oriundos da saúde mental, especificamente do cuidado com os(as) adolescentes que apresentavam sinais de ansiedade e depressão: Seja um GuardaChuva na vida de alguém.

Nesta linha de pensamento, ressaltamos a aproximação as Epistemologias do Sul (2018) no sentido de problematizar e confrontar o imaginário colonial moderno que solapa as tentativas de construção de uma educação emancipatória (GONÇALVES, et al., 2020). Por outro lado, essa aproximação também se posiciona paralelamente à perspectiva de saúde defendida por Noronha, Meneses e Nunes (2019), que entendem a saúde para além da lógica do reducionismo biomédico dicotomizado da vida humana. 
Assim, a partir dessa compreensão admitimos como pressuposto a ideia de que qualquer forma de universalismo e, aqui falamos da ótica biomédica, emerge de uma racionalidade monocultural. Partindo dessa configuração, ao pensar a contraposição ao colonialismo insidioso e a sua forma evanescente, (SANTOS, 2018, p. 2), estamos pensando no coletivo dos(as) sujeitospraticantes da escola e, na contraposição ao enfrentamento do pensamento que procura colonizar e excluir pessoas, culturas e universos simbólicos.

Optamos por organizar o arcabouço epistemológico-metodológico considerando dois desafios propostos por Santos (2006): primeiro, enfrentar o desperdício de experiências do mundo, uma vez que a racionalidade metonímica ao tomar a parte pelo todo, trabalha com um conceito de totalidade deixando de fora qualquer experiência que não se enquadra no padrão vigente; segundo, criar condições objetivas para uma transformação social, pois ao considerar a visibilização desta experiência social o estudo se articula à sociologias das ausências e, simultaneamente a sociologia das emergências e a ecologia dos saberes, porque se projeta a partir de uma ação prospectiva para que outros coletivos partam das práticas desenvolvidas pelo grupo investigado e reinventem novas formas de ser e estar no mundo.

Nessa lógica, para atender tais pressupostos, optamos pela visibilização das produções dos sujeitospraticantes do cotidiano escolar como maneiras plurais de narrar o mundo. Privilegiar as narrativas se deve pela aproximação ao pensamento de Beatriz Sarló (2006) que valoriza a narração de modo a acessar a memória como uma forma de testemunho do vivido e, portanto, a ruptura com um modo de fazer a 'História' pelo alto, desconsiderando as experiências daqueles que estiveram subalternizados (SPIVAK, 2010).

Ao privilegiar as imagens e narrativas (BENJAMIN, 1994) que efetivamente participaram das ações educativas, privilegiaremos as "obras artísticas imagéticas - pinturas e fotografias - entendidas como meio de evitar as armadilhas dos textos escritos e suas verdades neutras e objetivas" (OLIVEIRA; GERALDI, 2010, p. 23). Por fim, buscamos também nas redes sociais da escola sinais, pistas, indícios (GINZBURG, 1989), das práticas emancipatórias do coletivo estudado.

\section{CORPOREIDADE[3] E O COTIDIANO ESCOLAR: OUTROS SABERES, OUTRAS MANEIRAS DE CUIDAR}

\footnotetext{
O coletivo é formado pelos próprios alunos, que explicaram que o nome "girassóis" foi escolhido porque o girassol, além de representar a felicidade, está sempre voltado para a luz e de costas para a escuridão. O coletivo realiza trabalhos de grupo com alunos e, durante o Setembro Amarelo, estará visitando as salas de aula explicando a importância da mobilização.
}

A epígrafe apresentada é um recorte do Boletim Informativo [4] sobre o seminário que reuniu especialistas das áreas de psiquiatria e atendimento de emergência para falar sobre prevenção ao suicídio. Talvez para alguns, trazer a referida produção e o reconhecimento do conhecimento científico, por intermédio dos especialistas da área de Psiquiatria, fosse o ápice do trabalho. Todavia, entendemos que ao fazer isso, mais uma vez estaríamos buscando a referência na monocultura do saber e rigor científico (SANTOS, 2006).

Desse modo, ao trazer de início tal produção, buscamos salientar que privilegiaremos a potência e o reconhecimento do ato de cuidar na ótica daqueles que o produziram e participaram de múltiplas maneiras de pensarfazer o cuidado no cotidiano da escola aqui investigada. 
Cabe frisar que, o projeto iniciou em 2019, a partir da demanda criada por uma estudante da escola, conforme narrativa da pedagoga da escola:

E aí na reunião, ela falou que essa ideia surgiu porque elaconvivia com muitos
colegas que tinham pensamentos suicidas, muitos colegas se automutilavam,
tristes, deprimidos. (Pedagoga da Escola - Entrevista concedida pelo WhatsApp dia
$02 / 12 / 2020$ ). Grifos do autor.

A narrativa supramencionada nos remete a dois aspectos mencionados por Santos (2018) e que, ao nosso ver, estão entrelaçados: a ecologia dos saberes e o processo de democratização da escola.

Com relação a ecologia dos saberes a narrativa apresenta sinais que evidenciam que a experiência da estudante (AP) a permitiu perceber o que estava acontecendo com os(as) colegas. Desse modo, ao compreendermos que a escola privilegia um saber que emerge da estudante, considerarmos que há aí a aproximação a ecologia dos saberes.

Do mesmo modo, nos parece que a escola trabalhou enredada ao pensamento pósabissal, uma racionalidade que nos remete a aprender com o Sul, isto é, aprender com aqueles que, na interação com a razão indolente, foram historicamente invisibilizados(as) e/ou descredibilizados(as) por serem desfavorecidos de conhecimentos (SANTOS, 2018).

Diante do exposto, torna-se relevante trazer Larrosa (2002) para o diálogo, no intuito de entendermos a diferença entre experiência e vivência. Para o autor experiência é tudo aquilo que nos passa, ou nos toca, isto é aquilo que marca nossa corporeidade e nos faz intervir no mundo. Assim a experiência não é sinônimo da vivência, visto que nesta última aquilo que nos passa não adquire sentido e significado, não se torna fruto de racionalização.

Portanto, vamos entender que a experiência de AP é um conhecimento a ser considerado, um saber potente que permitiu a intervenção na realidade em que ela estava inserida. Um indício (GINZBURG, 1989) do que estamos a problematizar emergiu em uma reportagem das alunas MC e D para o jornal da Cleusa:

Figura 2 - Aluna A.P.

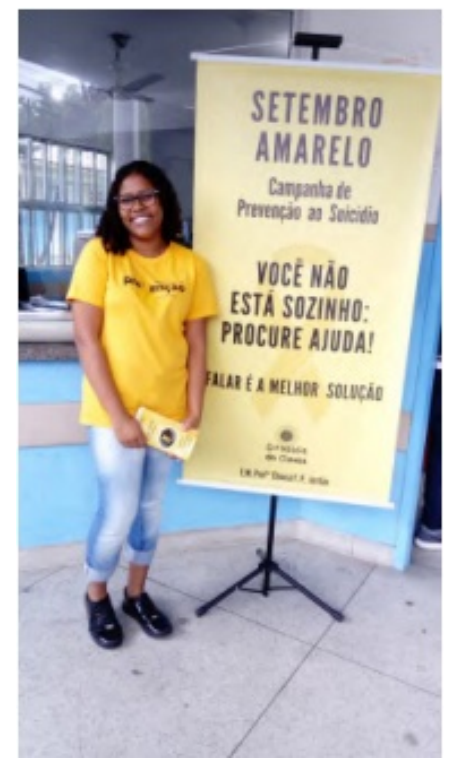

Fonte: Jornal da escola - out/ 2019, p. 2

Jornal (MC e D): O que motivou vocês a criarem esse coletivo?

Girassóis: A aluna AP que teve a iniciativa de criar o grupo, ela tinha ansiedade e 
assim como ela venceu ela quer ver outras pessoas vencerem a ansiedade e a depressão também. (Jornal - E.M.C.F.P.J, out/ 2019, p. 2).

A entrevista do jornal realizada com a AP nos permite perceber que a estudante já havia tido a experiência com a ansiedade e os problemas oriundos desse transtorno, talvez o que a possibilitou desenvolver o olhar aguçado para encontrar dentre os(as) seus pares os sinais de sofrimento e dor. A esse respeito Barsaglini $(2019$, p. 2) nos chama a atenção para o fato de que diversas "coisas que se passam escapam à objetivação, reflexão porque se encontram no plano das sensações e somente são sentidas/vividas no fluir da vida [...]", daí entender a disposição de AP para torna-se uma agente na criação dos Girassóis:

Jornal (MC e D): Qual é a origem do nome?

Girassóis: "Girassóis" é uma flor que gera alegria, e transmite paz, sendo que fica de costas para o escuro e de frente para a luz (Jornal - E.M.C.F.P.J, out/ 2019, p. 2).

Figura 3 - Material de divulgação do Coletivo Girassóis da Cleusa

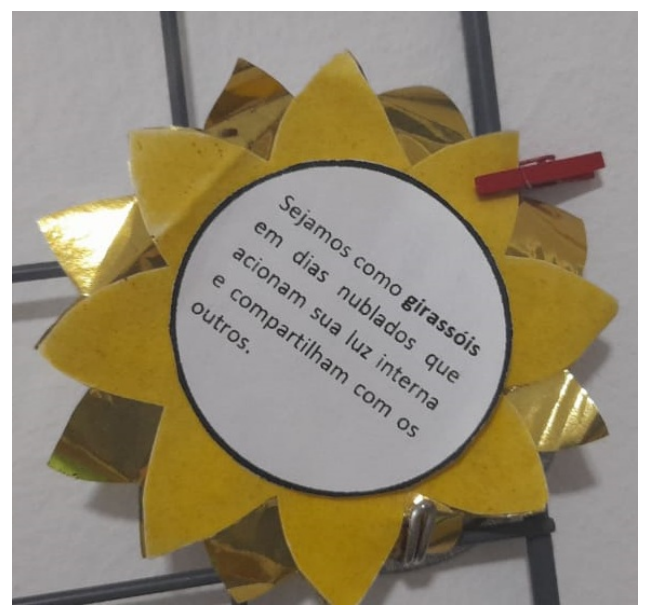

Fonte: Arquivo Iconográfico da escola

Pautados na contraposição da lógica que opera invisibilizando abissalmente e resgatando o lugar do 'outro' que procura o seu espaço de existência, nos parece que o coletivo da escola buscou transformar o 'Setembro Amarelo' em um espaço político e efetivo de construção de conhecimento, estabelecendo a contraposição ao colonialismo.

Ao tecer tal assertiva - contraposição ao colonialismo -, estou a considerar também o segundo aspecto citado, a democratização do cotidiano escolar, pois ao validar o saber dos(as) estudantes a escola rompeu com a hierarquização de saber e poder. A narrativa da Pedagoga (S) da E.M.C.F.P.J, nos permitiu acessar tais processos:

Uma outra ação que desenvolvemos foi a ida as salas. Essa ação foi muito bacana...porque assim: primeiro que os Girassóis nasceu das necessidades dos alunos, da articulação dos alunos, partiu desses sujeitos...a escola na realidade deveria ser pensada partindo das ações deles. [...] mas eles que fizeram tudo, que mobilizaram a escola. Então, no mês de setembro eles foram a todas as turmas, eles confeccionaram o material, eles selecionaram o vídeo. [...] E a partir do material produzido eles foram as salas com o nosso apoio, levaram a televisão, conversaram com cada turma... (PEDAGOGA DA ESCOLA - Entrevista concedida pelo WhatsApp dia 02/12/2020).

A narrativa apresentada nos parece um indício de uma prática com potencial emancipatório, visto o seu consentimento para a livre organização dos estudantes, permitindo o que Santos (2018, p. 84) indica sobre o processo de democratização como espaço emancipatório articulado com a democratização estrutural. 
A comunidade escolar, assim, - a equipe diretiva, docentes, direção, funcionários(as) de apoio, estudantes -, ampliou o espaço de participação do coletivo dos Girassóis na escola ao ampliar a escuta do que o grupo trazia para contribuir com o trabalho educativo da 'Cleusa'. A escola partilhou com o Coletivo dos Girassóis alguns encaminhamentos sobre o ato de cuidar e, desse modo, o grupo conseguiu acessar as repercussões simbólicas/ imateriais desse transtorno silencioso que envolve o suicídio.

A narrativa da Pedagoga (S) revela as intervenções dos Girassóis que tornaram os(as) estudantes mais atentos ao que se passava com o(a) 'outro(a)' colega:

\begin{abstract}
Enquanto escola, os alunos começaram a ficar mais atentos com os colegas que manifestavam comportamento entristecido ou com os colegas que eles ficavam sabendo que estavam se auto mutilando colegas que deixavam alguma recado...colocavam alguma coisa no facebook, no status do Whatsapp ou Instagram. [...] Por fim, a AP e uma outra aluna também tiveram a iniciativa de fazer uma roda de conversa com os colegas...e aí elas conduziram a roda, ouviram, mediaram...algumas situações foram encaminhadas pra gente (grupo de pedagogos) e a gente encaminhou para a Secretaria de Educação no intuito de obter apoio (Pedagoga da Escola - Entrevista concedida peloWhatsApp em $02 / 12 / 2020)$.
\end{abstract}

A roda de conversa (Fig. 4), como um espaço de produção de conhecimento e 'cuidado', oferece credibilidade aos saberes produzidos a partir da diferença colonial (MIGNOLO 2003). A perspectiva dialógica (FREIRE, 1997) prioriza a comunicação e o compartilhamento como elemento fundante na relação que se estabelece entre os sujeitos que coabitam o mundo.

Figura 4 - Roda de Conversa

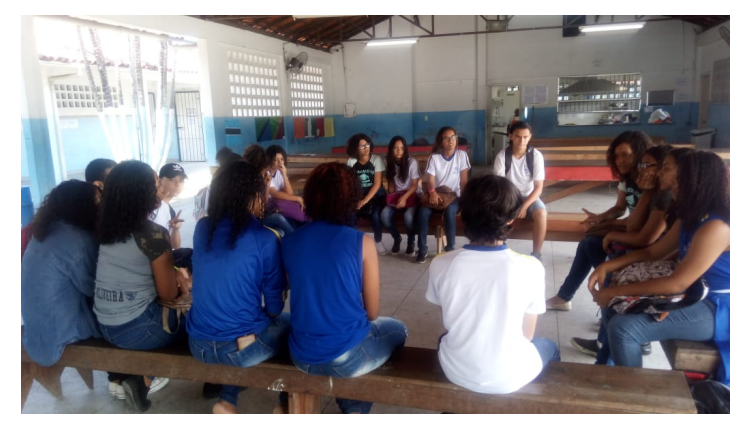

Fonte: Arquivo da escola

Ressalto ainda que, ao priorizar a roda de conversa, me parece que o grupo optou pelo processo de decodificação da realidade, visto que, para Freire (2003, p. 113) cabe ao mediador não apenas ouvir, mas desafiar aqueles envolvidos no processo: "problematizando, de um lado, a situação existencial codificada e, de outro, as próprias respostas que vão dando aqueles no decorrer do diálogo".

Desse modo, o círculo de cultura não ensina, aprende-se em reciprocidade de consciências. Tal metodologia permite a partilha de experiências e o desenvolvimento de reflexões sobre as práticas educativas dos sujeitos em um processo mediado pela interação e compartilhamento com os pares, resguardando a esses sujeitos um lugar de fala (SPIVAK, 2010), garantindo o espaço de co-criação dos processos de fabricação das produções do projeto.

\title{
REFERÊNCIAS
}

ALVES, Nilda. Decifrando o pergaminho: o cotidiano das escolas nas lógicas das redes cotidianas. In: oliveira, I B.; Alves, N. (orgs.). Pesquisa no/do cotidiano das escolas: sobre 
redes de saberes. Rio de Janeiro: DP\&A, 2001.

BARSAGLINI, Reni. Repercussões dos adoecimentos crônicos nos estudos de experiência: tipos, momentos e mediadores. Oficina do CES, n. 452, p. 1-27, 2019.

BENJAMIN, Walter. O narrador. In: BENJAMIN, Walter. Magia e técnica, arte e política: ensaios sobre literatura e história da cultura. 7. ed. São Paulo: Brasiliense, 1994. p. 197-221.

GONÇALVES, Francisca Tatiana Dourado et al. Imagem corporal feminina e os efeitos sobre a saúde mental: uma revisão bibliográfica sobre a intersecção entre gênero, raça e classe. Revista Eletrônica Acervo Saúde, n. 39, p. e2194-e2194, 2020.

LARROSA, Jorge. Notas sobre a experiência e o saber de experiência. Revista Brasileira de Educação. n. 19, p. 20-28, 2002.

MENESES, Maria Paula G. "Quando não há problemas, estamos de boa saúde, sem azar nem nada: para uma concepção emancipatória das saúde e das medicinas." In SANTOS, Boaventura de Sousa (org.). Semear outras soluções: os caminhos da biodiversidade e dos conhecimentos rivais. Rio de Janeiro: Civilização Brasileira, 2005.

MIGNOLO, Walter D. Histórias locais/Projetos globais: colonialidade, saberes subalternos e pensamento liminar. Belo Horizonte: Ed. UFMG, 2003.

NORONHA, Susana de, MENESES, Maria Paula; NUNES, João Arriscado. Health and the Epistemologies of the South. Portugal: University of Coimbra/Centre for Social Studies (CES), 2019.

OLIVEIRA, I. B. GERALDI, J. W. Narrativas: outros conhecimentos, outras formas de expressão. In OLIVEIRA, I. B (Org.) Narrativas: outros conhecimentos, outras formas de expressão. Petrópolis: RJ: DP et Alii: Rio de Janeiro: FAPERJ, 2010.

SANTOS, B. S. A gramática do tempo: Para uma nova cultura política. São Paulo: Cortez, 2006.

- O Colonialismo e o século XXI. Outras palavras. 2018. Disponível em: https://outraspalavras.net/geopoliticaeguerra/boaventura-o-colonialismo-e-o-seculo-xxi/.

SARLÓ, B. Tiempo pasado: cultura de la memória y giro subjetivo. Buenos Aieres, Siglo XXI, 2006.

SPIVAK, Gayatri Chakravorty. Pode o subalterno falar?. Belo Horizonte: Editora UFMG, 2010.

[1] O Jornal é uma produção dos(as) estudantes a partir da iniciativa e mediação do professor Fabio Braga de Língua Portuguesa da Escola Municipal Cleusa Fortes de Pinho Jordão.

[2] Ao trabalhar com a grafia a partir da junção de palavras estou me aproximando da perspectiva enunciada pela professora Nilda Alves (2001), que busca a superação da dicotomização herdada da ciência moderna, que separa e dicotomiza, por exemplo: pensarfazer, espaçotempo, dentre outras.

[3] Ao optarmos pela corporeidade, nos aproximamos da noção de 'sujeito encarnado', pois entendemos que o 
ser humano emerge do processo de enação - mergulho no mundo - e da multidimensionalidade da experiência (NAJMANOVICH, 2001).

[4] Publicado em - 04/09/2019 pela Superintendência de Comunicação da PMAR. 